\title{
Undergraduate Study of Thermal Conductivity of Metals
}

Estudo da condutividade térmica de metais a nível de graduação

\author{
T. B. Ferrari, S. H. Hara, J. L. Aziani, L. Rocha, \\ E. de Paula and M. Mulato \\ Departamento de Física e Matemática, Faculdade de Filosofia Ciências e Letras de Ribeirão Preto, \\ Universidade de São Paulo, Av. Bandeirantes 3900, Ribeirão Preto, 14040-901, Brazil
}

Recebido em 7 de maio, 2002. Aceito em 7 de junho, 2002.

\begin{abstract}
In this work we analyze an undergraduate experiment used to determine the thermal conductivity of metals $(\mathrm{K})$. We introduce few modifications in order to offer the student the chance to explore different models, learning the basic scientific method of developing appropriate and improved explanations for each experiment in order to better link theory and empirical results. Semi-empirical corrections are introduced in the system in order to check the experimental results according to previously reported $\mathrm{K}$ values. As specific cases we use copper $\left[\mathrm{K}=0.92 \mathrm{cal} /\left({ }^{\circ} \mathrm{C} \mathrm{s} \mathrm{cm}\right)\right]$, aluminum $\left[\mathrm{K}=0.49 \mathrm{cal} /\left({ }^{\circ} \mathrm{C} \mathrm{s} \mathrm{cm}\right)\right]$ and brass $\left[\mathrm{K}=0.26 \mathrm{cal} /\left({ }^{\circ} \mathrm{C} \mathrm{s} \mathrm{cm}\right)\right]$ cylinders.

Nesse trabalho analisamos um experimento de graduação que é utilizado para se determinar a condutividade térmica de metais $(\mathrm{K})$. Introduzimos algumas modificações a fim de oferecer ao estudante a oportunidade de explorar diferentes modelos, de forma a aprender o básico do método científico de desenvolvimento de explicações apropriadas, e melhoradas para cada experimento com o objetivo de obter uma melhor afinidade entre teoria e resultados experimentais. Correções semiempíricas são introduzidas no sistema a fim de comparar os resultados experimentais com outros previamente tabelados. Como casos específicos utilizamos cilindros de cobre $\left[\mathrm{K}=0.92 \mathrm{cal} /\left({ }^{\circ} \mathrm{C} \mathrm{s}\right.\right.$ $\mathrm{cm})]$, alumínio $\left[\mathrm{K}=0.49 \mathrm{cal} /\left({ }^{\circ} \mathrm{C} \mathrm{s} \mathrm{cm}\right)\right]$ e latão brass $\left[\mathrm{K}=0.26 \mathrm{cal} /\left({ }^{\circ} \mathrm{C} \mathrm{s} \mathrm{cm}\right)\right]$.
\end{abstract}

\section{Introduction}

During the high-school classes around the world, most of the activities are still based on the classic seminarlike presentation by the teacher. Most of the courses are based on theoretical classes, where only a very low percentage of the students have the chance to explore any kind of practical demonstration or experimentation. Even in the best cases, the approach is very superficial. The amount of experimental studies increases at the undergraduate level, specially considering Physics and Chemistry classes. It can thus be said that the first contact of the students with the scientific method of investigation occurs during the basic laboratory undergraduate physics courses.

The classes of experimental physics are normally developed in parallel with the theoretical classes during the same term or semester. In this sense, most of the times it is assumed that the students perform their experiments after the comprehension of all the physical concepts behind the theory, as well as the development of all the equations, etc. Unfortunately, history shows that this is not always the case because the students do not prepare themselves properly before the laboratory classes. They seem to have the behavior of collecting the data first, and trying to understand them latter as a homework. This philosophy must be changed, although this is not an easy task. Even in the best cases, after collecting all the necessary data and substituting them into the respective equations in order to check the validity of the last (or the validity of the description of the physical phenomena), in many occasions the students find a disagreement between the prediction of the theory and their findings in the laboratory. Most of the time this fact happens not because the physical laws are wrong, and not also because the experiment was wrongly performed. This happens indeed because the physical model is incomplete or too simple to explain the whole experimental work. As two typical examples it can be said that during the classes of mechanics very often the model does not take into account nonconservative forces, and during the classes of thermodynamics very often the model does not take into account the loss of energy by heat conduction at some surface or interface, and so on.

The important fact about the situation is that the students cannot visualize or imagine where the discrepancy comes from: they cannot easily identify the miss- 
ing concepts. The students adopt either one of two procedures during their reports: a) they state that the experiment is very bad, the available tools and equipments are inappropriate, the results are consequently very poor and they cannot verify what they wanted, thus blaming the experimental errors more than they should or could; b) they try to adopt the opposite way of thinking, i.e., considering the many possible errors in the experiment, they try to create a larger error bar in order to justify any mismatch according to this maneuver.

Regardless of any of the above, most of the time the students try to blame the experiment and the experimental data in a way to protect the set of theoretical equations as a holly statement. Only a very small percentage of the students have in fact the courage to face the problem and try to look for the real explanation, even though this seems to be a hard work for them. Some times they can even elaborate a list of possible causes for the observed mismatch, but do not have the feeling of how each one of them would contribute to a final experimental value higher or lower than expected. In general, they have trouble trying to quantify the possible causes of disagreement between expected values and observed data.

In order to try to help to solve the above problem, the present paper discusses a simple experiment and procedure of analysis that are suggested for laboratory classes where the students are introduced to the scientific method based on the determination of the thermal conductivity of metals.

The experiment deals with the ancient problem of thermal conduction through a metallic cylinder whose ends sit at temperatures $\mathrm{T} 1$ and $\mathrm{T} 2$ where $\mathrm{T} 1>\mathrm{T} 2$ as shown in Fig. 1 (where $\mathrm{L}$ is the cylinder length and $\mathrm{D}$ its diameter). Assuming an isolated system, the heat exchange can be written as $[1,2]$ :

$$
\frac{\Delta Q}{\Delta t}=-K \frac{A}{L} \Delta T
$$

where $\Delta \mathrm{Q} / \Delta \mathrm{t}$ is the heat transfer per unit time, $\mathrm{K}$ is the thermal conductivity of the material, $\mathrm{A}$ is the surface area, $\mathrm{L}$ is the total length of the cylinder, and $\Delta \mathrm{T}$ is the temperature difference between the two faces, i.e. $\Delta \mathrm{T}=\mathrm{T} 1-\mathrm{T} 2$.

In this work we review a simple experiment that can be used to determine $\mathrm{K}$ for different metallic materials where the theoretical model expressed by equation 1 represents only a first approximation to the reality. The main differences between theory and experimental facts can be explored by the student in a scientific way.

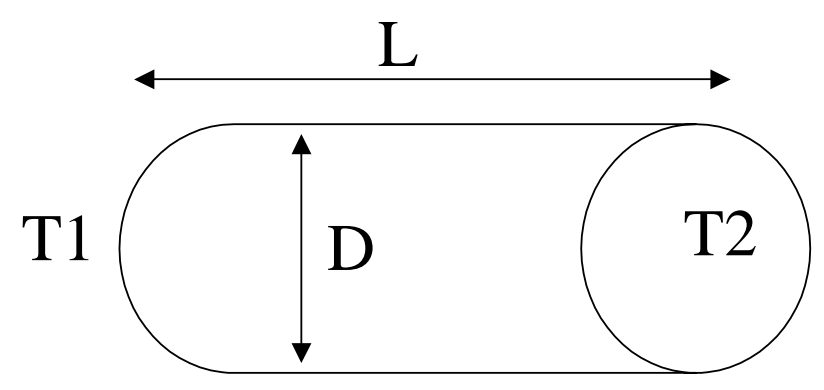

Figure 1. Illustration of a metallic cylinder of length L and diameter $\mathrm{D}$, whose faces sit at temperatures $\mathrm{T} 1$ and $\mathrm{T} 2$. Heat conduction occurs from face 1 to face 2 given that $\mathrm{T} 1>\mathrm{T} 2$.

\section{Experimental}

The experimental setup consists of a metallic cylinder (diameter D, and length $\mathrm{L}$ as shown in Fig. 1) that is used to connect two cups as illustrated in Fig. 2. For all the experiments presented in this work it was always adopted $\mathrm{D}=15.85 \pm 0.01 \mathrm{~mm}$ and $\mathrm{L}=61.00 \pm 0.01 \mathrm{~mm}$. Cup 1 is made of aluminum and it is filled with water $(\mathrm{M} 1=300 \pm 1 \mathrm{ml})$ at room temperature. The water temperature inside Cup 1 is going to be referred as $\mathrm{T} 1$, and it is monitored by the use of a thermometer. Cup 2 is made of Teflon [3-5] and it weights $\mathrm{M}_{C 2}$. It has also a Teflon cover with a hole for the introduction of a thermometer $\left( \pm 0.5^{\circ} \mathrm{C}\right)$ that is used to monitor the temperature (T2) of a fixed amount of water (M2) inside Cup 2.

Cup 1 is heated by a flame until the water inside it starts to boil. At this moment an stirrer is introduced inside Cup 2. This stirrer consists of a small ferromagnetic cylinder covered with a thin layer of epoxy. Under Cup 2 sits a rotating magnet that is used to induce the movement of the stirrer inside Cup 2. In the sequence, small cubes of ice are introduced inside Cup 2, and a chronometer is started. After all the ice has melted an increase in temperature $\mathrm{T} 2$ is observed, and thus the system is under an almost stationary condition. A table is constructed containing each degree of variation of $\mathrm{T} 2$, the respective $\mathrm{T} 1$ and the elapsed time since the beginning of the experiment. The table of the present paper (not shown) was constructed from T2 equal to 0 up to $36^{\circ} \mathrm{C}$. Note that higher T2 final values could also be used.

At the end of the experiment the amount of water inside Cup $2\left(\mathrm{M}_{2}\right)$ was measured. We used $\mathrm{M}_{2}$ values of $145.0 \pm 0.5 \mathrm{ml}, 135.0 \pm 0.5 \mathrm{ml}$ and $112.0 \pm 0.5 \mathrm{ml}$ for the experiments performed with brass, aluminum and copper cylinders, respectively. Note that in order to avoid burning accidents the external part of the cylinder was protected by a thin Teflon layer between the two cups (approximately $1 \mathrm{~mm}$ thick). After the construction of the table with the results of the exper- 
imental data, different models were applied for their understanding as presented in the next sections.

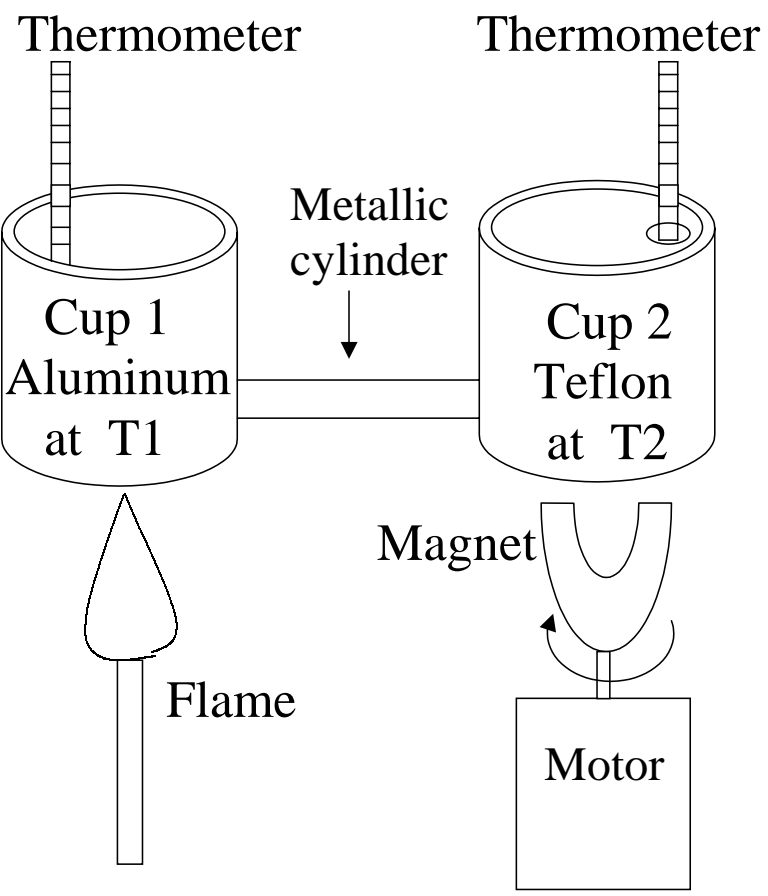

Figure 2. Schematic drawing corresponding to the experimental set-up. Cup 1 made of aluminum is filled with water and heated by a flame while its temperature is monitored by a thermometer T1. Cup 2 is made of Teflon, which is also filled with ice and water. It has a Teflon cover and its temperature T2 is also monitored. Heat is transferred from Cup 1 to Cup 2 through the metallic cylinder. A stirrer is used for a better temperature homogenization inside Cup 2.

\section{Results and Discussion}

\section{III.1 The simplest model}

We observed that for the case of a copper (aluminum/brass) cylinder the system takes about 800 (1350/1840) seconds for the heating of T2 from $0{ }^{\circ} \mathrm{C}$ up to $36^{\circ} \mathrm{C}$. These are important numbers that help the professor during the preparation of the classes. In order to determine $\mathrm{K}$ using the theoretical model predicted by equation $1, \Delta \mathrm{Q}$ can be calculated using the approximations that all the heat that is transferred from Cup 1 through the metallic cylinder is stored in the water inside Cup 2. According to that simple model, for each variation of $\mathrm{T} 2$ by one degree, $\Delta \mathrm{Q}$ can be written as $[6,7]$ :

$$
\Delta Q=M_{2} C_{W} \Delta T_{W}
$$

where $\mathrm{C}_{W}$ is the specific heat of water (equal to $1 \mathrm{cal} / \mathrm{g}^{\circ} \mathrm{C}$ ) and $\Delta \mathrm{T}_{W}$ is the increase in temperature equal to $1^{\circ} \mathrm{C}$. For each material $\mathrm{K}$ can be determined by substituting equation 2 into equation 1 . We name this model as model 1 , and thus $\mathrm{K}$ is denoted as $\mathrm{K}_{1}$ and written as:

$$
K_{1}=\left(M_{2} C_{W} \Delta T_{W} L\right) /(\Delta T A \Delta t)
$$

Note that in equation (3) most of the parameters are constants, besides $\Delta \mathrm{T}$ and $\Delta \mathrm{t}$ (assuming $\Delta \mathrm{T}_{W}$ as $\left.1^{\circ} \mathrm{C}\right)$.

Figure 3 shows the results of $K_{1}$ as a function of $\mathrm{T} 2$ for copper (squares), aluminum (circles) and brass (triangles) respectively. Three different regions named $\mathrm{A}, \mathrm{B}$ and $\mathrm{C}$ are illustrated in Fig. 3, and they are separated by the vertical dashed lines. Each of them will be considered separately next. The data for $\mathrm{T} 2<$ $5{ }^{\circ} \mathrm{C}$ were not shown in region $\mathrm{A}$. They were excluded from the graph because region A represents a regions where the system in not in equilibrium yet (a mixture of water and ice exists inside cup2, that also presents a temperature gradient), thus K1 values start from close to zero and reach the equilibrium value at about $\mathrm{T} 2$ equal to $5^{\circ} \mathrm{C}$. In this sense, region $\mathrm{A}$ is totally disregarded. Regions $\mathrm{B}$ and $\mathrm{C}$ are separated according to room temperature, that was about $27^{\circ} \mathrm{C}$.

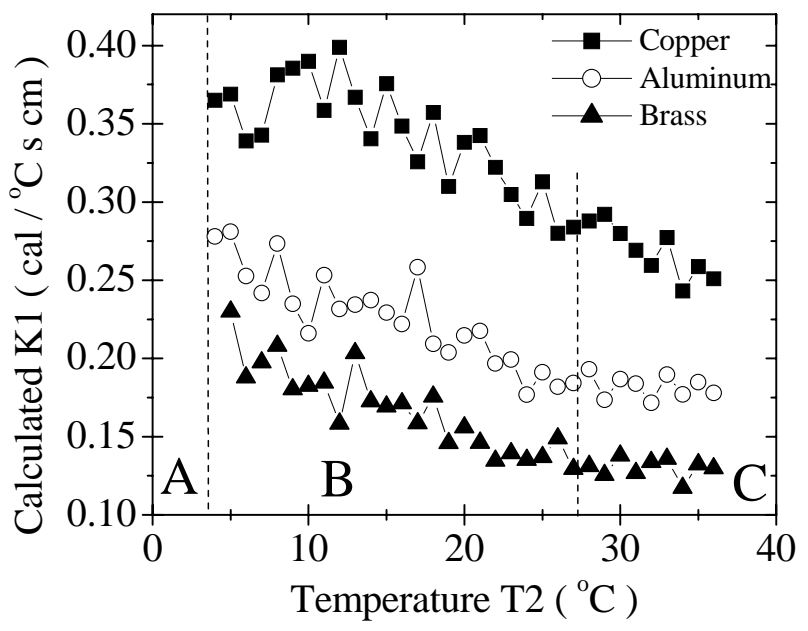

Figure 3. Experimentally obtained thermal conductivity values (K1) according to the simplest theoretical model described by equations 1 and 2 (see text) for three metallic cylinders made of copper (squares), aluminum (circles) and brass (triangles) as a function of the temperature (T2) inside Cup2. Vertical dashed lines separate three regions: a) non-equilibrium region; b) quasi-equilibrium region for $\mathrm{T} 2$ smaller than room temperature; c) quasi-equilibrium region for T2 higher than room temperature. Note that the obtained $\mathrm{K} 1$ are neither constant nor linear as a function of $\mathrm{T} 2$, in disagreement with the theory.

It can be observed from Fig. 3 that the experimental $K_{1}$ is neither constant nor linear as a function of T2. This finding is in total disagreement with the predicted theoretical model. On top of that the experimentally obtained $\mathrm{K}_{1}$ maxima are considerably smaller 
than those reported for copper $\left[0.92 \mathrm{cal} /\left({ }^{\circ} \mathrm{C} \mathrm{sec} \mathrm{cm}\right)\right]$, aluminum $\left[0.49 \mathrm{cal} /\left({ }^{\circ} \mathrm{C}\right.\right.$ sec $\left.\left.\mathrm{cm}\right)\right]$ and brass $[0.26 \mathrm{cal}$ $\left./\left({ }^{\circ} \mathrm{C} \mathrm{sec} \mathrm{cm}\right)\right][8]$. The difference between reported and experimentally determined values are bigger, the higher the reported $K$ value. At this moment the student is lead to think about the experimental results, and is also lead to try to understand them and to formulate new models that would better explain the data.

\section{III.2 The influence of the Teflon Cup}

The model needs a correction in region $\mathrm{B}$ because the total increase in $\mathrm{T} 2$ is due to the heat conduction through the metallic cylinder $\left(\triangle \mathrm{Q}_{C Y L I N D E R}\right)$, plus the heat conduction from the Teflon $\operatorname{Cup}\left(\Delta \mathrm{Q}_{C U P}\right)$ because the internal part of the Teflon Cup sits at T2 while the outmost part sits at room temperature (which is higher than T2). In this sense, the total heat transferred to the water inside Cup 2 can be written as:

$$
\Delta Q_{W A T E R}=\Delta Q_{C Y L I N D E R}+\Delta Q_{C U P}
$$

$\triangle \mathrm{Q}_{C Y L I N D E R}$ calculated from equation 4 can be substituted into equation $1 . \Delta \mathrm{Q}_{W A T E R}$ is calculated as in equation 2 , and $\Delta Q_{C U P}$ is calculated as:

$$
\Delta Q_{C U P}=\frac{K_{T E} A_{T E}}{d_{T E}} \Delta T_{T E} \Delta t
$$

where $\Delta \mathrm{t}$ is the same time interval as before, $\Delta \mathrm{T}_{T E}$ is the temperature difference between the internal and external walls of the Teflon Cup, $\mathrm{d}_{T E}$ is the thickness of the walls of the Cup $(7.5 \mathrm{~mm}), \mathrm{K}_{T E}$ is the thermal conductivity of Teflon $\left(4.53 \times 10^{-4} \mathrm{cal} /\left({ }^{\circ} \mathrm{C} \mathrm{s} \mathrm{cm}\right)\right)$, and $\mathrm{A}_{T E}$ is the effective area of the cup in contact with the water inside it. This area can be written as the sum of the lateral and the bottom areas, and can be approximated by the following equation using an average cup radius $R_{T E}(37.2 \mathrm{~mm})$ :

$$
A_{T E}=2 \pi R_{T E} H+\pi R_{T E}^{2}
$$

where $\mathrm{H}$ is the height of the water column inside Cup 2 $(76.1 \mathrm{~mm})$. Note that the cup is not totally filled with water, and the top of the cup is not in contact with the water inside it. According to the above, the right $\triangle \mathrm{Q}_{C Y L I N D E R}$ to be used in equation 1 would be given by:

$$
\Delta Q_{C Y L I N D E R}=M_{2} C_{W} \Delta T_{W}-\left\{\frac{K_{T E}}{d_{T E}}\left(2 \pi R_{T E} H+\pi R_{T E}^{2}\right) \Delta T_{T E} \Delta t\right\}
$$

what suggests an even worse result than the one observed in Fig. 3, given that a smaller $\triangle Q_{C Y L I N D E R}$ would be obtained. We will come back to that further below.

The model needs to be corrected for region $\mathrm{C}$ also, but in this case the total heat transferred through the metallic cylinder is basically divided in three parts: a) part of it is used to increase the water temperature inside Cup $2\left(\Delta \mathrm{Q}_{W A T E R}\right)$; b) part of it is used to increase the temperature of the cup itself $\left(\Delta Q_{C U P_{-} A}\right)$, and c) part of it is lost due to the mechanism of heat transfer through Cup 2 to the atmospheric environment $\left(\Delta \mathrm{Q}_{C U} P_{-} B\right)$. Thus, $\Delta \mathrm{Q}_{C Y L I N D E R}$ can be written as:

$$
\Delta Q_{C Y L I N D E R}=\Delta Q_{W A T E R}+\Delta Q_{C U P_{-} A}+\Delta Q_{C U P_{-} B}
$$

where $\Delta \mathrm{Q}_{W A T E R}$ is calculated as in equation 2 , and $\triangle Q_{C U P_{-} B}$ is calculated as in equation 5 .

In order to calculate $\Delta Q_{C U} P_{-} A$ we assume a linear temperature distribution though the thickness of the Teflon cup as illustrated by the solid line in Fig. 4(a). We also assume that for each $\Delta \mathrm{t}$ the temperature distribution varies qualitatively according to the dashed line in Fig. 4(a), once that the temperature of the internal wall increases by $1^{\circ} \mathrm{C}$, and the temperature of the external wall stays at room temperature. Of course this is just a first simple approximation, since the higher the value of the temperature of the internal wall of the cup, the bigger the difference between the temperature of the external wall and the external ambient. This is going to be latter addressed in more detail. According to this first approximation, the total heat stored inside the cup material itself would be given by:

$$
\Delta Q_{C U P_{A}}=\int_{0}^{d_{T E}} \rho_{T E} A_{T E} C_{T E} \Delta T(x) d x=\rho_{T E} A_{T E} C_{T E} \int_{0}^{d_{T E}} \Delta T(x) d x
$$


where $\rho_{T E}$ is the mass density of Teflon $\left(2200 \mathrm{~kg} / \mathrm{m}^{3}\right)$, $\mathrm{A}_{T E}$ is given by equation $6, \mathrm{C}_{T E}$ is the specific heat of Teflon $\left(0.28 \mathrm{cal} /\left(\mathrm{g}^{\circ} \mathrm{C}\right)\right)$, and $\Delta \mathrm{T}(\mathrm{x})$ is the temperature variation inside the thickness of the cup as a function of the length for $0 \leq \mathrm{x} \leq \mathrm{d}_{T E}$. In order to solve the above integral, $\Delta \mathrm{T}(\mathrm{x})$ must be known. This information can be extracted from Fig. 4(a) using the difference between the two equations that describe each of the linear dependence of $\mathrm{T}$ with $\mathrm{x}$ before and after $\Delta \mathrm{t}$. According to that, the initial distribution of temperature would be given by:

$$
\Delta T(x)=T 2(x)-T 1(x)=T_{I N T \_2}-T_{I N T \_1}+\left\{\frac{T_{I N T \_1}-T_{I N T \_}}{d_{T E}}\right\} x
$$

Taking into account that the variation from $\mathrm{T}_{I N T_{-} 1}$ to $\mathrm{T}_{I N T \_2}$ is equal to $1^{\circ} \mathrm{C}$, equation 12 can be reduced to:

$$
\Delta T(x)=1-\frac{x}{d_{T E}}
$$

The substitution of equation 13 into equation 9 leads to:

$$
\Delta Q_{C U P_{-} A}=\rho_{T E} A_{T E} C_{T E} \int_{0}^{d_{T E}} 1-\frac{x}{d_{T E}} d x=\rho_{T E} A_{T E} C_{T E} \frac{d_{T E}}{2}
$$

Then, the expression for $\Delta \mathrm{Q}_{C Y L I N D E R}$ can be obtained by substituting equations 2,5 and 14 into equation 8 :

$$
\Delta Q_{C Y L I N D E R}=M_{2} C_{W} \Delta T_{W}+\left\{\frac{K_{T E}}{d_{T E}}\left(2 \pi R_{T E} H+\pi R_{T E}^{2}\right) \Delta T_{T E} \Delta t\right\}+\rho_{T E} A_{T E} C_{T E} \frac{d_{T E}}{2}
$$

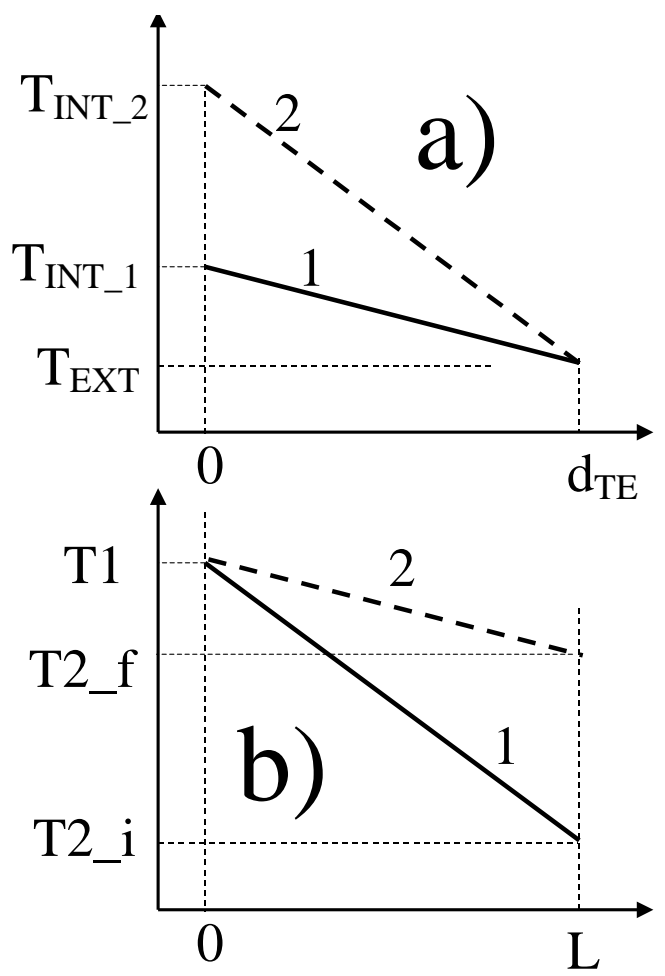

Figure 4. Schematic illustration of temperature distribution: a) from the inner surface of the Teflon wall of Cup 2 to the outer surface; and b) along the extension of the metallic cylinder from Cup 1 to Cup 2. The solid line (numbered 1) represents the initial temperature distribution and the dashed line (numbered 2) represents the final temperature distribution after the time interval $\Delta t$, for both curves. In a) the horizontal axis corresponds to the wall thickness (from 0 to $\mathrm{d}_{T E}$ ); $\mathrm{T}_{E X T}$ is the external temperature, $\mathrm{T}_{I N T \_1}$ and $\mathrm{T}_{I N T \_2}$ are the internal initial and final temperatures respectively. In $\mathrm{b}$ ) the horizontal axis corresponds to the cylinder length (from 0 to $\mathrm{L}$ ); $\mathrm{T} 1$ is the constant temperature of Cup $1 ; \mathrm{T}_{2 \_} i$ and $\mathrm{T}_{2_{-} f}$ are the initial and final temperatures of Cup 2 respectively.

At this moment the student should be able to perform new calculations taking into account the contribution of each different mechanism described so far. We do not present these data here. Instead, we move one step further and discuss in the next section extra mechanisms that must also be taken into account for the construction of a better model. 


\section{III.3 Losses through the cylinder}

Two other different mechanisms exist, besides the heat conduction from cup 1 to cup 2 by the metallic cylinder. The first of them regards the heat that is lost through the surface of the cylinder $\left(\Delta \mathrm{Q}_{S U R F}\right)$ (in its radial direction, i.e. along the vertical arrow in Fig. 1) because, in principle, each section of the cylinder sits at a temperature $\mathrm{T}$ higher than room temperature. The second mechanism regards the storage of heat inside the metallic cylinder itself $\left(\triangle \mathrm{Q}_{S T O R E D}\right)$ as previously described for Cup 2. In this sense, the total heat lost $\left(\Delta \mathrm{Q}_{L O S T}\right)$ can be written as:

$$
\Delta \mathrm{Q}_{\mathrm{L}_{O S T}}=\Delta \mathrm{Q}_{\mathrm{SURF}}+\Delta \mathrm{Q}_{\mathrm{STORED}}
$$

The heat lost through the surface $\Delta \mathrm{Q}_{S U R F}$ is one of the most difficult to be quantified, mainly because of its three-dimensional character. As a very rough approximation, it could be said that the heat transfer rate at each section of the cylinder (i.e. in its radial direction) would be given, as in the case of equation 1 , by $[1,2]$ :

$$
\frac{\Delta Q_{S U R F}}{\Delta t}=-K \frac{A_{S E C}}{L_{S E C}} \Delta T(x)
$$

where $\Delta t$ is the elapsed time as before, $\mathrm{K}$ is the thermal conductivity of the metallic cylinder, $\Delta \mathrm{T}(\mathrm{x})$ is the temperature difference between the highest temperature inside each section of the cylinder and room temperature, $\mathrm{A}_{S E C}$ is an effective area and $\mathrm{L}_{S E C}$ is an effective length for the heat transfer, respectively. Just as a simple approximation it could be assumed that: a) $\mathrm{A}_{S E C}$ can be approximated by the perimeter of the section at position $\mathrm{x}$, i.e., $\mathrm{A}_{S E C}=\pi \mathrm{D}$; and $\mathrm{b}$ ) the highest temperature inside the section is localized at the cylinder axis, i.e., a linear gradient of temperature will be assumed for each section with the highest temperature value sitting at the cylinder axis and the lowest temperature value sitting at the external surface thus leading to $\mathrm{L}_{S E C}=\mathrm{D} / 2$. It is obvious that this is not the exact case, and thus extra discussion about these approximations is needed. Anyway, according to the above $\Delta \mathrm{Q}_{S U R F}$ could be written as:

$$
\Delta Q_{S U R F}=\int_{0}^{L} \frac{K 2 \pi D}{D} \Delta t \Delta T(x) d x=2 \pi K \Delta t \int_{0}^{L} \Delta T(x) d x
$$

Note that $\mathrm{L}$ in equation 18 refers to the cylinder length between the two cups.

In order to solve the above equation $\Delta \mathrm{T}(\mathrm{x})$ must be known. Applying the same approximation as in the previous section, $\Delta \mathrm{T}(\mathrm{x})=\mathrm{T}_{I N T}-\mathrm{T}_{E X T}$, and $\mathrm{T}_{I N T}$ can be approximated by a linear function of $\mathrm{x}$ as:

$$
T_{I N T}=T 1-a x, \quad \text { with } \quad a=\frac{T 1-T 2}{L}
$$

Then $\Delta Q_{S U R F}$ can be finally written as:

$$
\Delta Q_{S U R F}=2 \pi K \Delta t \int_{0}^{L}\left(T 1-T_{E X T}\right)-\left(\frac{T 1-T 2}{L}\right) x d x=2 \pi K L \Delta t\left(T 1-T_{E X T}-\frac{T 1-T 2}{2}\right)
$$

On the other hand, the heat stored inside the cylinder itself $\Delta \mathrm{Q}_{\text {STORED }}$ can be calculated using the same procedure as before for the case of Cup 2. The only difference now is the fact that the temperature distribution inside the cylinder and its variation after $\Delta \mathrm{t}$ would be illustrated by Fig. 4(b). According to Fig. 4(b), $\Delta \mathrm{T}(\mathrm{x})$ could be written as:

$$
\Delta T(x)=T 1-\left(\frac{T 1-T 2 \_f}{L}\right) x-\left\{T 1-\left(\frac{T 1-T 2 \_i}{L}\right) x\right\}=\frac{x}{L}\left(T 2 \_f-T 2 \_i\right)=\frac{x}{L}
$$

because the difference between $\mathrm{T} 2 \mathrm{f}$ and $\mathrm{T} 2 \mathrm{i}$ is always kept equal to $1^{\circ} \mathrm{C}$.

The heat stored in each section of the metallic cylinder can be written as:

$$
\Delta Q(x)=\rho_{M} \pi\left(\frac{D}{2}\right)^{2} C_{M} \Delta T(x)
$$

where $\rho_{M}$ and $\mathrm{C}_{M}$ are the mass density and specific heat of the metallic cylinder, respectively. $\rho_{M}\left(\mathrm{C}_{M}\right)$ is equal to $8400(0.090), 2700(0.215)$ and $8920(0.092) \mathrm{kg} / \mathrm{m}^{3}$ (cal/ $\left.\left(\mathrm{g}{ }^{\circ} \mathrm{C}\right)\right)$ for the case of brass, aluminum and copper, respectively [8]. The total stored heat can be calculated by the integration of equation 22 along the whole extension $\mathrm{L}$ of the cylinder from Cup 1 to Cup 2, after the substitution of equation 21 into 22: 


$$
\triangle Q_{\text {STORED }}=\int_{o}^{L} \rho_{M} \pi\left(\frac{D}{2}\right)^{2} C_{M} \frac{x}{L} d x=\rho_{M} \pi\left(\frac{D}{2}\right)^{2} C_{M} \frac{L}{2}
$$

The substitution of equations 20 and 23 into equation 16 leads to the final $\Delta \mathrm{Q}_{L O S T}$ :

$$
\Delta Q_{L O S T}=2 \pi K L \Delta t\left(T 1-T_{E X T}-\frac{T 1-T 2}{2}\right)+\rho_{M} \pi\left(\frac{D}{2}\right)^{2} C_{M} \frac{L}{2}
$$

For region B, all contributions (equations 7 and 24) discussed in the last two sections add up as:

$$
\begin{gathered}
\Delta Q_{C Y L I N D E R}=M_{2} C_{W} \Delta T_{W}-\left\{\frac{K_{T E}}{d_{T E}}\left(2 \pi R_{T E} H+\pi R_{T E}^{2}\right) \Delta T_{T E} \Delta t\right\}+ \\
2 \pi K L \Delta t\left(T 1-T_{E X T}-\frac{T 1-T 2}{2}\right)+\rho_{M} \pi\left(\frac{D}{2}\right)^{2} C_{M} \frac{L}{2}
\end{gathered}
$$

The substitution of equation 25 into equation 1 would lead to a final $\mathrm{K}$ value for region $\mathrm{B}$ of:

$$
K_{B}=\frac{\Psi}{\mathrm{Z}}
$$

where

$$
\Psi=M_{2} C_{W} \Delta T_{W}-\left\{\frac{K_{T E}}{d_{T E}}\left(2 \pi R_{T E} H+\pi R_{T E}^{2}\right) \Delta T_{T E} \Delta t\right\}+\rho_{M} \pi\left(\frac{D}{2}\right)^{2} C_{M} \frac{L}{2}
$$

and

$$
\mathrm{Z}=\frac{A}{L} \Delta t \Delta T_{W}-2 \pi L \Delta t\left(T 1-T_{E X T}-\frac{T 1-T 2}{2}\right)
$$

For region $\mathrm{C}$, on the other hand, all contributions (equation 15 and 24) discussed in the last two sections add up as:

$$
\begin{gathered}
\Delta Q_{C Y L I N D E R}=M_{2} C_{W} \Delta T_{W}+\left\{\frac{K_{T E}}{d_{T E}}\left(2 \pi R_{T E} H+\pi R_{T E}^{2}\right) \Delta T_{T E} \Delta t\right\}+\rho_{T E} A_{T E} C_{T E} \frac{d_{T E}}{2}+ \\
2 \pi K L \Delta t\left(T 1-T_{E X T}-\frac{T 1-T 2}{2}\right)+\rho_{M} \pi\left(\frac{D}{2}\right)^{2} C_{M} \frac{L}{2}
\end{gathered}
$$

The substitution of equation 29 into equation 1 would lead to a final $\mathrm{K}$ value for region $\mathrm{C}$ of:

$$
K_{C}=\frac{\Upsilon}{\mathrm{Z}}
$$

where

$$
\Upsilon=M_{2} C_{W} \Delta T_{W}+\left\{\frac{K_{T E}}{d_{T E}}\left(2 \pi R_{T E} H+\pi R_{T E}^{2}\right) \Delta T_{T E} \Delta t\right\}+\rho_{M} \pi\left(\frac{D}{2}\right)^{2} C_{M} \frac{L}{2}+\rho_{T E} A_{T E} C_{T E} \frac{d_{T E}}{2}
$$

and $\mathrm{Z}$ is given by equation 28 .

It is obvious that the models described above either for region $\mathrm{B}$ or $\mathrm{C}$ are not exact. In fact lots of approximations have been made just because it was assumed that the students do not have enough mathematical tools yet, given that this experiment could be performed during the first year (second semester) of the undergraduate course. In fact, the present authors have already adopted this experiment as part of a laboratory course called Laboratório de Física II, at the DFMFFCLRP-USP with great success for two semesters.
Note that even though the mathematical models are not correct, the most important physical mechanisms for heat conduction and heat storage have been identified. Thus the calculations presented so far represent a way of inducing the students to the continuous interrogation of the experimental results and to the continuous development of better and more specific models. As a simple example, starting with the analysis of region B, the students can easily observe by simple substitution of the variables' values into the equations that the second term of $\mathrm{Z}$ given by equation 28 is overestimated. 
According to that, $\mathrm{Z}$ would have a final negative value, lacking any real physical significance. This shows that $\triangle \mathrm{Q}_{S U R F}$, as obtained by equation 20 is overestimated mainly due to the incorrect temperature distribution inside each section of the cylinder as presented by equations 18 and 19.

In order to better understand the system, a different approach can be adopted by a huge turn in the experiment. The students can: a) adopt the reported $\mathrm{K}$ values as known constants; b) introduce a function $\mathrm{F}(\mathrm{T} 2)$ that would represent the correction that must multiply the second term of $\mathrm{Z}$ in equation 28 for the right answer, thus leading to a new function called Z2; and c) determine $\mathrm{F}(\mathrm{T} 2)$ using expressions 26,27 and the corrected equation 28. Note that a new semi-empirical model for the second term of equation 28 would be obtained this way.

Curiously, after the proper substitution, the obtained $\mathrm{F}(\mathrm{T} 2)$ is a linearly decreasing function of $\mathrm{T} 2$ in the region $5 \leq \mathrm{T} 2 \leq 27^{\circ} \mathrm{C}$ for the three cylinders, i.e., $\mathrm{F}(\mathrm{T} 2)=\mathrm{a}-\mathrm{b} . \mathrm{T} 2$. Fig. 5 presents the experimental data for the case of the aluminum cylinder only. The corresponding coefficients of the linear fits for the case of the three metallic cylinders are presented in the inset of Fig. 5. Note that each metallic cylinder has its own set of fitted parameters, indicating that the correction function $\mathrm{F}(\mathrm{T} 2)$ is in fact a function of the cylinder material also.

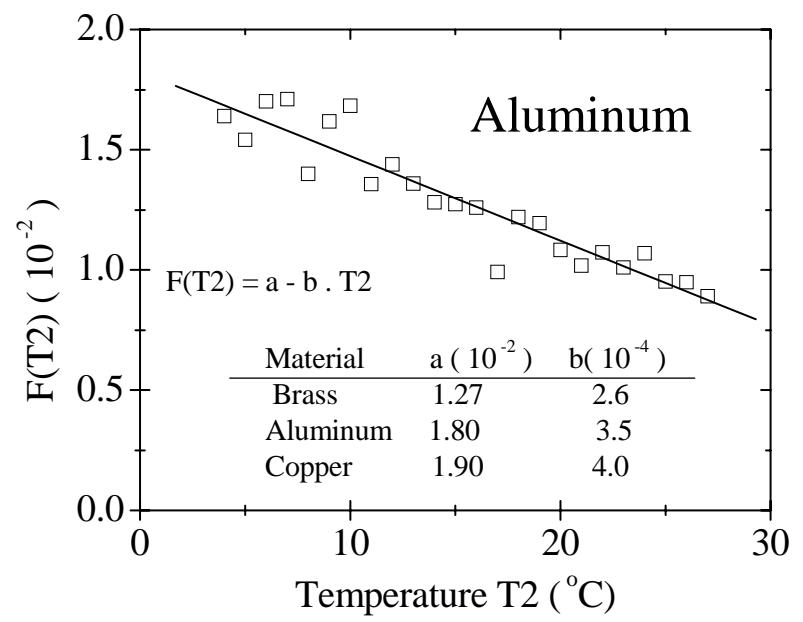

Figure 5. Empirical function $\mathrm{F}(\mathrm{T} 2)$ as a function of the temperature inside Cup 2 for the correction of the second term in equation 28 (for the analysis of region B in Figure 3 ) for the case of an aluminum cylinder. Note that F(T2) is a linear function of $\mathrm{T} 2$, the same being true for the case of the other metallic cylinders. The corresponding fitting parameters are given at the inset.

The fitted parameters a and $\mathrm{b}$ are plotted in Fig. 6 as a function of each reported $\mathrm{K}$ value, where the cylinder material is also identified. Parameter a is plotted as solid squares at the left axis, while parameter $\mathrm{b}$ is plotted as open triangles at the right axis. It is also interesting to observe the non-linear variation of both parameters as a function of the reported $\mathrm{K}$ value, indicating that once again the cylinder material itself plays a very important hole. Note that both $\mathrm{a}$ and $\mathrm{b}$ parameters increase with $\mathrm{K}$, and that while the ratio of the highest to lowest reported $\mathrm{K}$ value is about 3.5, the ratio of highest and lowest a (or b) parameters is less than 2. The dashed line in Fig. 6 is only a guide for the eyes, and no fitting was tried because of the limited amount of experimental data. Finally, the final semiempirical correction to the second term of equation 28 would depend on two variables ( $\mathrm{K}$ and $\mathrm{T} 2$ ) as:

$$
F(T 2, K)=a(K)-b(K) \cdot T 2
$$

regardless of other parameters intrinsically related to the geometry of the system.

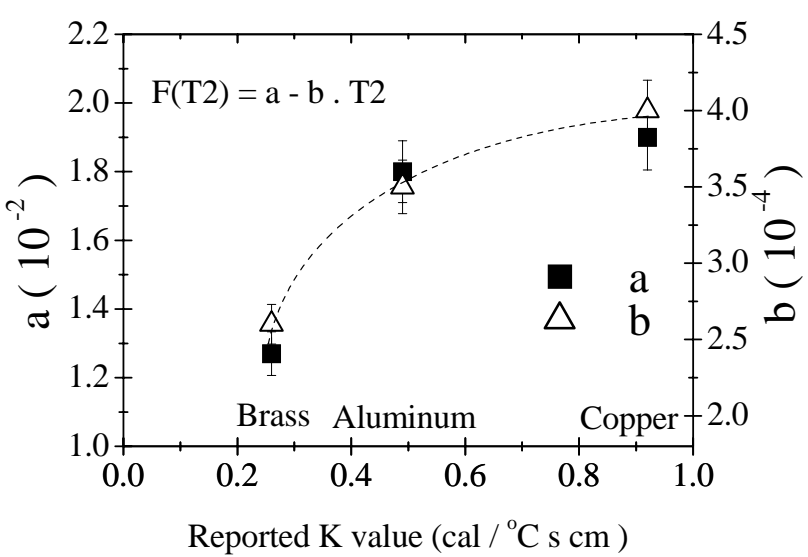

Figure 6. Fitted parameters of $\mathrm{F}(\mathrm{T} 2)$ for the case of the three metallic cylinders (as presented in the inset of Fig. 5) plotted as a function of the corresponding thermal conductivity of each material, the last ones obtained from the literature (see text).

Note that although an experimental function is found, the students cannot totally understand its physical meaning and origin, what can contribute to their own stimulation for the following courses of physics, mathematics and numerical calculus.

Moving to the analysis of region $\mathrm{C}$, the corrected $\mathrm{Z} 2$ term should be used in place of $\mathrm{Z}$ in equation 30 as discussed above. Nevertheless, even in this case, the $\mathrm{K}$ value calculated according to equation 30 is overestimated. The first three terms in equation 31 are basically the same as in equation 27 (the only difference being the fact that the second term is now added rather than subtracted in the whole expression). According to the previous discussion about region $\mathrm{B}$, these terms can be considered mathematically correct, and in this case, the only possibility of disagreement must come from the fourth term in equation 31. That is indeed the case as can be numerically confirmed: the fourth term in equation 31 is more than twice as big as the sum of the other three in the same expression. Thus, it is reasonable to assume that the fourth term has been the overestimated 
one. The main reason for that is the very simple (and incorrect) distribution of temperature inside the walls of Cup2 itself.

Following the same procedure as for region $\mathrm{B}$, the student can try to determine a function $\mathrm{G}(\mathrm{T} 2)$ that would multiply the fourth term in equation 31 , thus leading to a corrected $\mathrm{Y} 2$ value in substitution to $\mathrm{Y}$ in equation 31. Once again, a semi-empirical model would be obtained. In practice, once again the obtained function is linearly dependent on $\mathrm{T} 2$, and can be written as $\mathrm{G}(\mathrm{T} 2)=\mathrm{c}+\mathrm{d}$. T2. The fitted parameters $\mathrm{c}$ and $\mathrm{d}$ are plotted in Fig. 7 for the case of the three metallic cylinders. As in the previous case, the fitted parameters depend on the material also, and the final G(T2) could then be written as:

$$
G(T 2, K)=c(K)+d(K) . T 2
$$

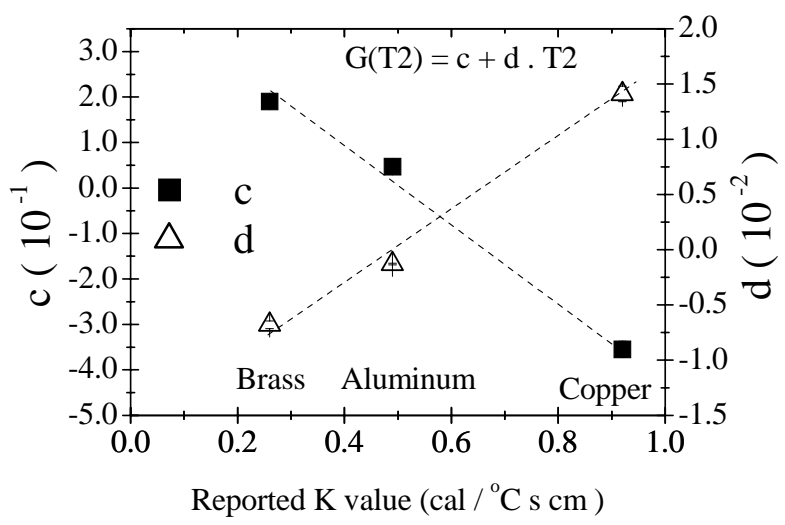

Figure 7. Fitted parameters of $\mathrm{G}(\mathrm{T} 2)$ for the case of the three metallic cylinders plotted as a function of the corresponding thermal conductivity of each material, the last ones obtained from the literature (see text). G(T2) is the empirical function that corrects the fourth term in equation 31.

Fig. 8 shows the final results for the case of the three metallic cylinders for a clear comparison of the models discussed. The K1 calculated according to equation 1 are shown as open squares. The final Kf calculated according to the corrections introduced for regions B and $\mathrm{C}$ are shown as solid squares, and the reported values for $\mathrm{K}$ for each material is shown as a solid line. The improvement of the semi-empirical model is outstanding.

The main reason behind the need for functions $F$ and $\mathrm{G}$ in the corrected models is the fact that the temperature distribution inside each section of the cylinder and inside the walls of Cup 2 were oversimplified. In order to better present a physical model the students need more mathematical and computational tools, not available for them yet during their first year of the undergraduate course.

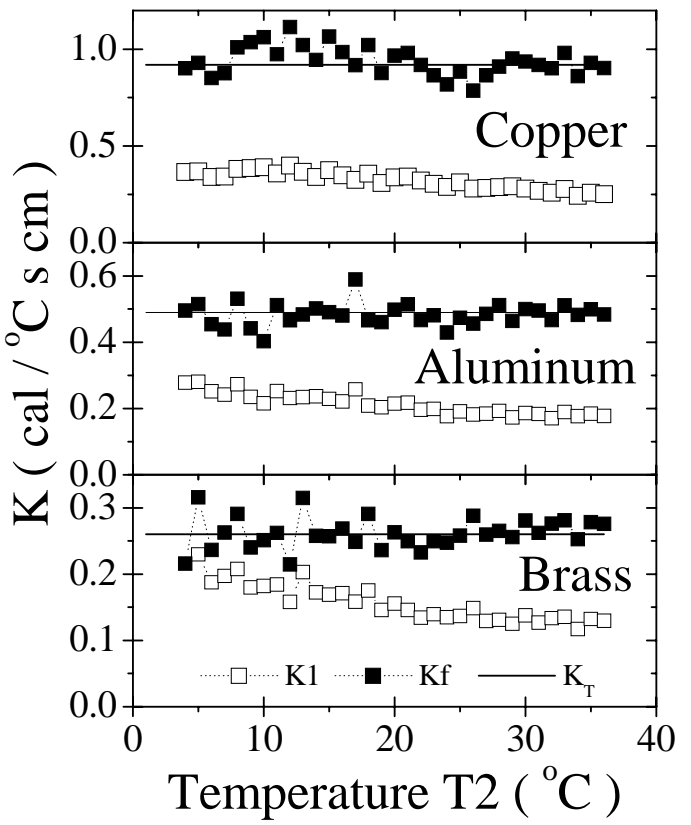

Figure 8. Comparison of the results that would be obtained with the simples model (K1, open squares) and with the model that takes into account several corrections, including the empirical functions $\mathrm{F}$ and $\mathrm{G}$ (Kf, solid squares). The thermal conductivity values obtained from the literature are shown as horizontal solid lines $\left(\mathrm{K}_{T}\right)$. Results are shown for the case of the three metallic cylinders (copper, aluminum and brass).

\section{Conclusion}

In fact, the findings of this experiment are important not because of the final results, but because they can show the students how complex a physics experiment can be even though it might look too simple from the beginning, and how simplified the theoretical models can be sometimes. This is an experiment that leaves student thinking about it even after the end of the class, and sure contributes to their self motivation during other classes of physics, math and numerical calculus. Finally, more than the simple verification of certain equations, the students are forced to think about the nature of many physical mechanisms during heat conduction.

\section{Acknowledgements}

This work was supported by the Brazilian agency CNPq.

\section{References}

[1] J. Carslaw, in Conduction of heat in solids, Second Edition, Oxford University Press, Oxford, p. 2 (1989).

[2] J. Phillips, in Examples in Applied Thermodinamics, The English Universities Press LTD, London, p. 74 (1960). 
[3] see

http://www.dupont.com/teflon/chemical/properties.html \#thermal

[4] see http://www.jenseninert.com/properties-teflon.htm

[5] see http://boedeker.com/ptfe_p.htm
[6] M. Planck, in Treatise on Thermodinamics, Dover Publications Inc., New York, p.35 (1945).

[7] E. Fermi, in Thermodinamics, Dover Publications Inc, New York, p.21 (1936).

[8] see ref [1] p.497 